\title{
Diffuse Alveolar Damage in the Evolution of Bronchopulmonary Dysplasia in the Baboon
}

\author{
J. J. COALSON, T. J. KUEHL, T. J. PRIHODA, AND R. A. DELEMOS
}

Department of Pathology, The University of Texas Health Science Center at San Antonio and Department of Physiology and Medicine, Southwest Foundation for Biomedical Research, San Antonio, Texas 78284

\begin{abstract}
Pulmonary immaturity, oxygen exposure that elicits cellular damage by free radicals, and barotrauma induced by mechanical ventilation are implicated in the pathogenesis of bronchopulmonary dysplasia. In the adult counterpart of adult respiratory distress syndrome, diffuse alveolar damage characterizes a histopathological sequence of lung findings that can occur during the disease course. Although adult respiratory distress syndrome has many etiologies, elevated oxygen exposure is known to be a contributor to the ensuing lung injury. In bronchopulmonary dysplasia, oxygen exposure is thought to be a primary agent of injury. The evolution of the histopathological findings in the premature baboon model of hyaline membrane disease/bronchopulmonary dysplasia was investigated in this study and compared to that in oxygen-treated adult baboons with adult respiratory distress syndrome. Findings from lung specimens of 121 prematurely delivered baboons at $0,0.5,1,2,3-6,7-11+$ days after delivery document that the premature lung has a delayed and more blunted exudative response when compared to that of human and baboon adults. Saccular edema, not hyaline membranes, is the dominant histopathological finding in the exudative phase of diffuse alveolar damage and occurs later (7-11 days) in infant lungs when compared to comparably treated adult lungs in which maximal exudative changes are seen at 3-6 days. The reparative response in the premature baboon is characterized by saccular wall thickening and fibrosis, with less intramural organization of exudate in saccular/alveolar spaces when compared to adults. The airway changes in the premature are more severe than those seen in adult disease. These findings indicate that diffuse alveolar damage does occur in the immature lung albeit with differing characteristics when contrasted to comparably injured adults. (Pediatr Res 24: $357-366,1988$ )
\end{abstract}

\section{Abbreviations}

DAD, diffuse alveolar damage

ARDS, adult respiratory distress syndrome

BPD, bronchopulmonary dysplasia

HMD, hyaline membrane disease

PPV, positive pressure ventilation

HFOV, high frequency oscillatory ventilation

HFFI, high frequency flow interruption

PTAH, phosphotungstic acid hematoxylin

PIE, pulmonary interstitial emphysema

PMN, polymorphonuclear leukocytes

Received January 29, 1988; accepted May 12, 1988.

Supported in part by NIH Grants HL29354, HL36536, and HL23578.

Correspondence Jacqueline J. Coalson, Ph.D., Department of Pathology, University of Texas Health Science Center, 7703 Floyd Curl Drive, San Antonio, TX 78284-7750.
During the late 1960 s and early 1970 s, the clinical syndrome called ARDS emerged. The influx of new treatment modalities had decreased the acute mortality of cardiovascular and renal failure in the intensive care setting, allowing the lung to emerge as the predominant failing organ after trauma and/or shock. Although Winternitz (1) had introduced the concept of diffuse alveolar damage in studies of dogs treated with war gases, it was Liebow and his colleagues, especially Katzenstein, who popularized the term and noted its association with ARDS and other conditions (2).

DAD is a descriptive term that reflects a consistent though nonspecific sequence of findings in the lung after acute injury by a variety of agents. In the adult it is separated into exudative and reparative (proliferative) phases (3). The 1- to 6-day exudative phase findings include pulmonary edema, hyaline membranes, alveolar wall edema, and microatelectasis. The reparative phase of DAD begins about 6 days postinjury and is characterized by hyperplasia of epithelial type II cells, and interstitial mononuclear inflammatory infiltrate and fibrocellular proliferation, and organizing alveolar exudates (3).

Chronic respiratory failure in the neonate can be seen in infants with HMD who go on to develop bronchopulmonary dysplasia (4). Of the multiple factors that have been suggested to cause BPD, pulmonary immaturity, oxygen exposure that elicits cellular damage via free radicals, and barotrauma induced by mechanical ventilation, continue to be prime considerations. Despite several shared etiologies of lung injury, especially oxygen toxicity, diffuse alveolar damage has not been identified in infants with HMD/BPD in the pediatric pulmonary literature.

The purpose of this study was to examine the evolution of the histopathological findings in immature lungs exposed to prolonged hyperoxia and conventional ventilation, and document if this model develops exudative and reparative DAD responses similar to those described in the humans with ARDS (5-7) and in the adult baboon treated with $100 \%$ oxygen $(8,9)$. We used a baboon model of HMD/BPD, in which animals are delivered prematurely by hysterotomy at 140 days \pm 2 days (term gestation

Table 1. Treatment groups

\begin{tabular}{lcc}
\hline & \multicolumn{2}{c}{ Treatment } \\
\cline { 2 - 3 } Day & PRN & $100 \% \mathrm{O}_{2}$ \\
\hline 0 & $5^{*}$ & \\
0.5 & $15 \dagger$ & 12 \\
1 & 16 & 6 \\
2 & 6 & 14 \\
$3-6$ & 18 & 14 \\
$7-11+$ & 15 & \\
\hline
\end{tabular}

* Never breathed.

$†$ PRN animals were intubated for approximately $48 \mathrm{~h}$ and received supplemental oxygen to maintain appropriate $\mathrm{PaO}_{2}$ levels. 
180 days) and treated with PPV and $100 \%$ oxygen. This regimen results in stage $3(4) \mathrm{BPD}$ pathological changes within a period of 11-17 days (10).

\section{MATERIALS AND METHODS}

During the past few years we have performed a series of controlled studies using the prematurely delivered baboon with HMD at study times of 5-7 h, $24 \mathrm{~h}, 96 \mathrm{~h}$, and 11 days (11-14). In addition, pilot experiments were performed to document the evolution of the disease process at birth ( 0 time), 6, 14, and 17 days of age, yielding a total of 121 premature baboons (Table 1). The early deaths that occurred in the 11-day study (usually as a result of airleak problems) provided study specimens for intermediate time points. In these animals lobes unaffected by the airleak lesions were examined by electron microscopy.

Details of the clinical management of this model have been published (11-14). Briefly, all animals were delivered by hysterotomy at $140 \pm 2$ days gestation, intubated with a $2.5-\mathrm{mm}$ endotracheal tube and placed on a time cycled, pressure limited, neonatal ventilator (Bear Cub, Bear Medical Systems, Inc., Riverside, CA). An umbilical artery catheter was inserted, intravenous fluids instituted, and baseline studies performed. For the long-term studies (11 days or longer, $11+$ days), a central venous catheter was inserted for fluid administration. After a 2 -h stabilization period, animals were assigned to various ventilators and treatment strategies using either PPV, HFOV (model SS-1, Texas Research, Inc., San Antonio, TX) or HFFI (Bird Space Tech-

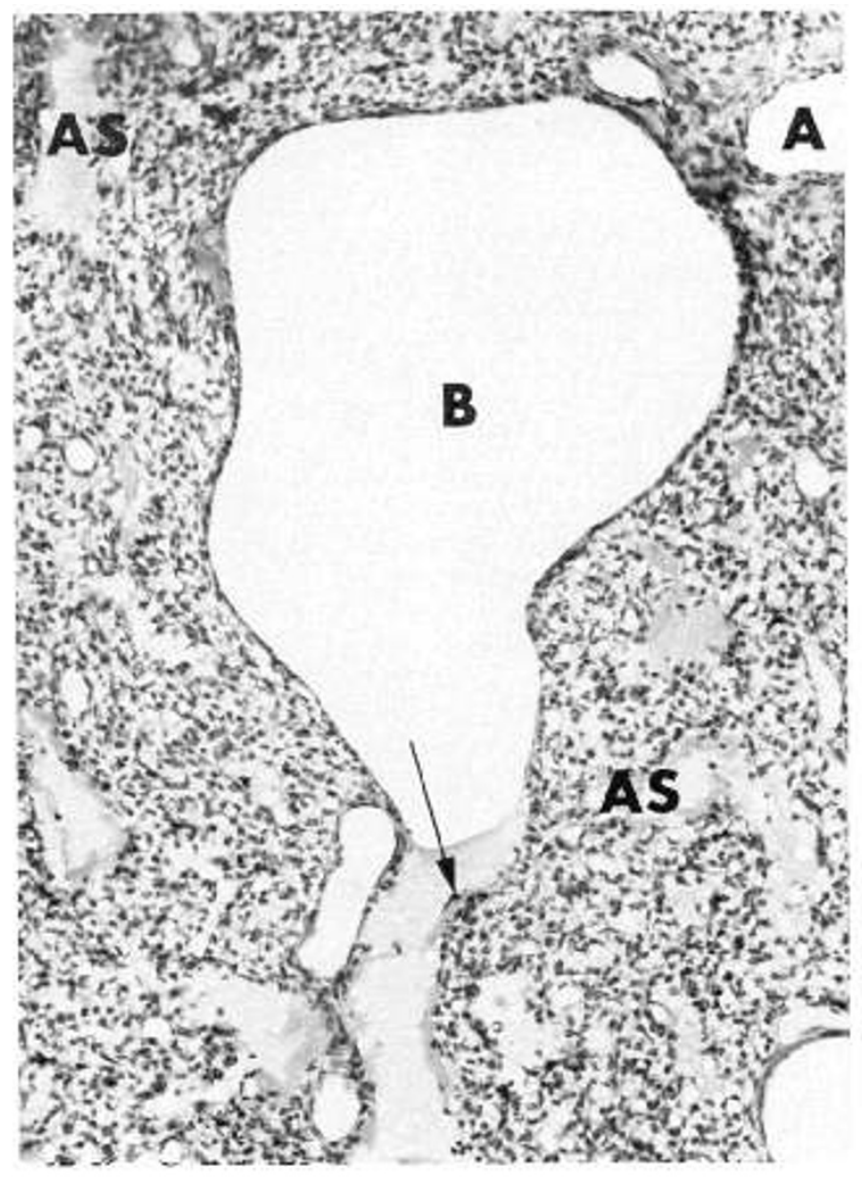

Fig. 1. A 5-h specimen. The bronchiole $(B)$ is dilated and its epithelium is markedly thinned. Several pyknotic cells are in the hyaline membrane (arrow). The saccules are collapsed, the partially opened ones $(A S)$ show hyaline membranes. $A$, pulmonary artery. Hematoxylin and eosin, $\times 150$.

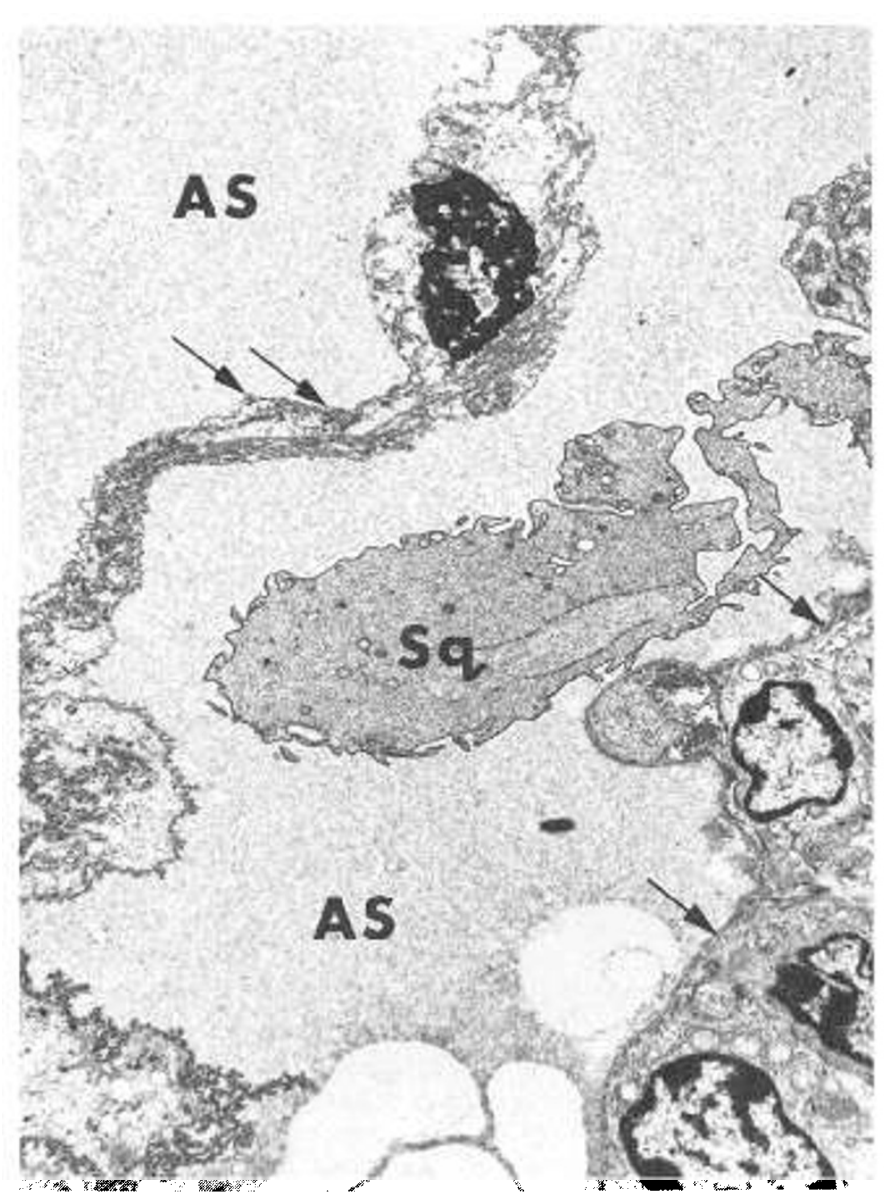

Fig. 2. A 5-h specimen. Ultrastructurally the degenerate alveolar (saccular) epithelium (double arrows) is lifted from its basement membrane (single arrows). The saccular $(A S)$ space is filled with edema. A squame $(S q)$ of amniotic fluid origin is floating in the edema fluid. Lead citrate and uranyl acetate, $\times 2470$.

nology, Sand Point, ID). All animals delivered for pilot studies were ventilated with conventional PPV.

Animals were paralyzed with pancuronium bromide and sedated with ketamine hydrochloride for the first $24-48 \mathrm{~h}$ and then allowed to breathe spontaneously thereafter. For invasive procedures, they were sedated with ketamine and given local anesthesia (xylocaine). The control animals were administered oxygen as needed (PRN) to keep their $\mathrm{PAO}_{2}$ between $50-80$ torr, whereas the other experimental groups received $100 \%$ oxygen for the duration of the designated study period. In general, all animals required a $\mathrm{FIO}_{2}$ of 50 during the first $24 \mathrm{~h}$ followed by $24 \mathrm{~h}$ of a $\mathrm{FIO}_{2}$ of 25 . Weaning from mechanical ventilation was attempted after $48 \mathrm{~h}$ in the PRN animals by decreasing the ventilatory rate and pressure in the PPV animals, and by decreasing the airway pressure and tidal volume in the high frequency groups. Usually there was no requirment for supplemental oxygen after extubation. Only a few animals required supplemental oxygen for a few hours until they could maintain a $\mathrm{PAO}_{2}$ over 50 torr on room air. Chest roentgenograms, arterial blood gases, routine clinical chemistry and hematological measurements, echocardiograms, and Doppler ultrasound examinations were performed at specified intervals and are described elsewhere (1416). Animals were maintained on ampicillin $(200 \mathrm{mg} / \mathrm{kg} / \mathrm{day})$ and gentamicin ( $5 \mathrm{mg} / \mathrm{kg} /$ day) for the duration of the experiments.

For the pathological studies, animals were killed by an overdose of anesthesia or, if the animals died unexpectedly, autopsies 
were performed within $45 \mathrm{~min}$ after death. Lung fixation for all the animals except those from the 6-day pilot study was accomplished by perfusion of quarter strength Karnovsky's fixative through the pulmonary vascular system while maintaining lung inflation at a constant transpulmonary pressure of $20 \mathrm{~cm}$ of water $(15,16)$. After opening the thorax and examining the lungs, the ductus arteriosus was ligated, the right ventricle was opened and a catheter secured in the main pulmonary artery. The left auricle was removed to allow the perfusate to escape. The lungs were slowly inflated and deflated three times using $20 \mathrm{~cm}$ of water pressure and were flushed of blood with an isosmotic/ isoncotic Hanks' balanced salt solution for approximately $1 \mathrm{~min}$. As the lungs were maintained at $20 \mathrm{~cm} \mathrm{H} \mathrm{H}_{2} \mathrm{O}$ transpulmonary pressure, the trachea was cross-clamped, and fixative was perfused for a minimum of $20 \mathrm{~min}$. After the perfusion, the entire heart/lung preparation was removed en bloc from the chest and floated in full strength Karovsky's until the lungs were cut and embedded for light and electron microscopic studies $24 \mathrm{~h}$ later. All other organs were examined and fixed in full strength Karnovsky's for microscopic studies.

The 6-day lung specimens were shared with other investigators so only the right lower lobe was available for pathological studies. These lungs were flushed with isosmotic/isoncotic Hanks' solution, the right lower lobe freed, its bronchus isolated, and full strength Karnovsky's fixative intratracheally instilled using 20

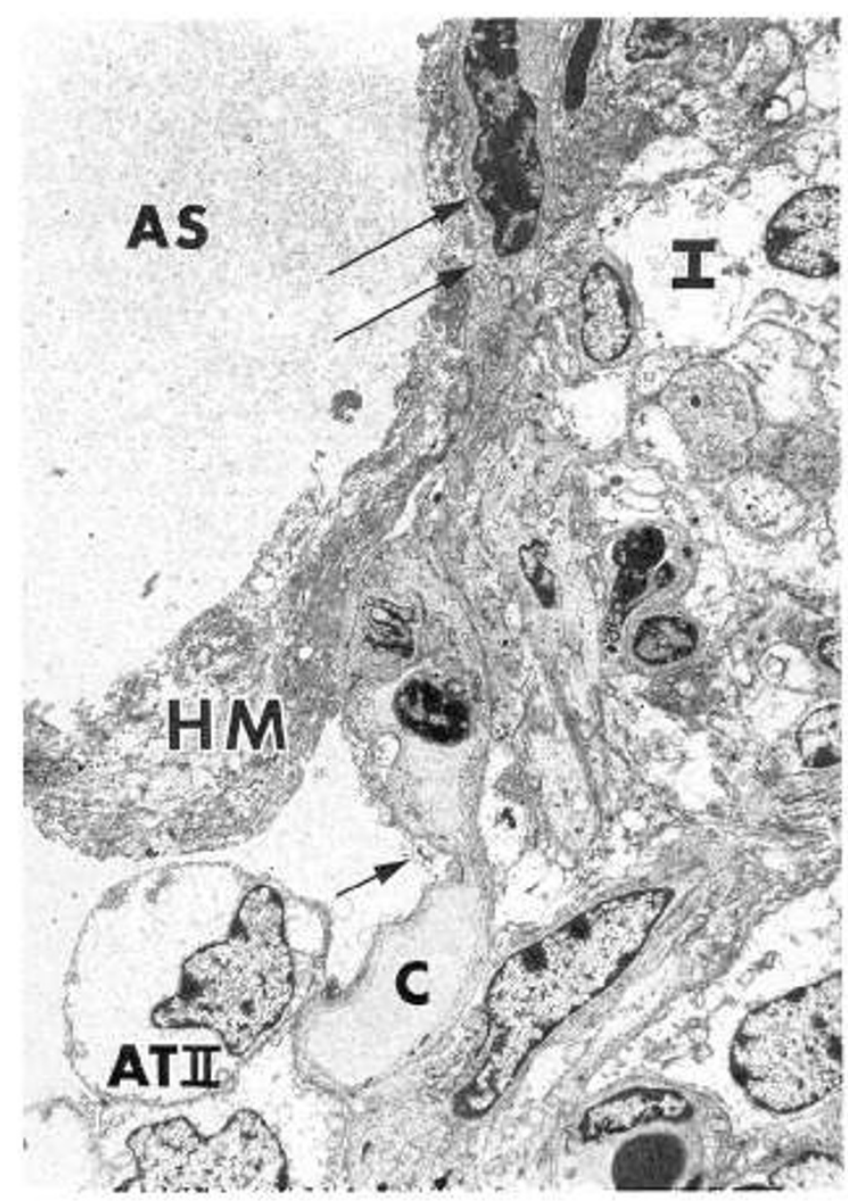

Fig. 3. A 6-h specimen. A hyaline membrane $(H M)$ composed of protein coagulum and degenerated cellular organelles is adhered to denuded basement membranes at one site (double arrows) and then extends over edematous type I epithelium (arrow) and a type II cell $(A T I I)$ that is devoid of lamellar inclusion bodies. The saccular space $(A S)$ is filled with edema and the interstitium $(I)$ contains many cellular elements. The endothelium of the capillary $(C)$ appears normal. Lead citrate and uranyl acetate, $\times 2470$.

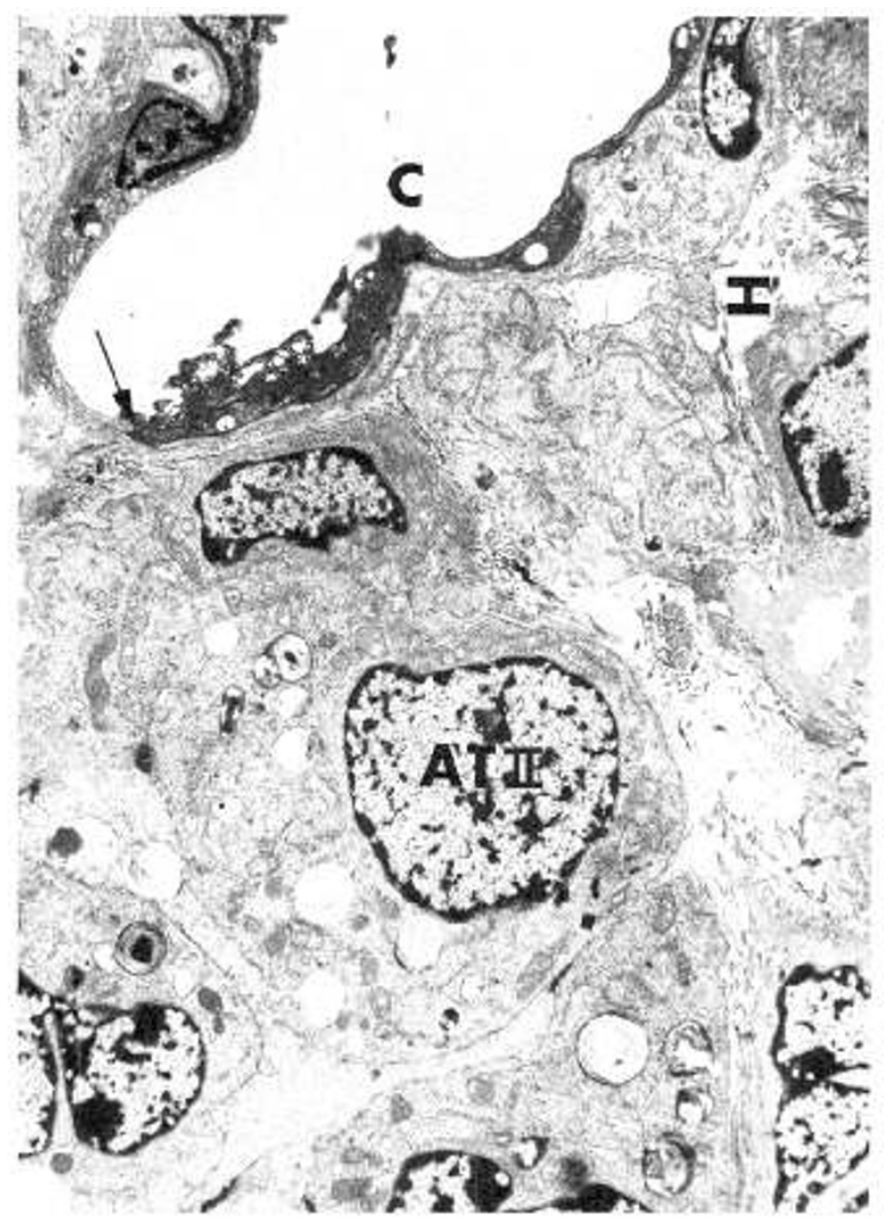

Fig. 4. A 48 -h $100 \% \mathrm{O}_{2}$-treated specimen. Endothelial damage is evident in the capillary $(C)$. An intercellular junction (arrow) clearly delineates the marked difference in cytoplasmic osmiophilia. The interstitium $(I)$ contains abundant cells and a few collagen fibers. Portions of three alveolar type II cells $(A T I I)$ are present. Lead citrate and uranyl acetate, $\times 3,120$.

$\mathrm{cm}$ of water pressure. The lungs were allowed to fix for $24 \mathrm{~h}$ and processed as described above for the perfusion fixed specimens.

After fixation, the lungs were weighed and the volumes determined by volume displacement (17). Mid-sagittal cross-sections of each lobe were taken and the entire surface blocked for embedment in paraplast. The blocks were cut at $4 \mu \mathrm{m}$ and the sections stained with hematoxylin and eosin and Masson-elastica connective tissue stain. Five- to 7-h, $24 \mathrm{~h}$, and 8- to 11-day PRN and $100 \% \mathrm{O}_{2}$ specimens were stained with Mallory's PTAH stain for fibrin.

For electron microscopic studies, 30 blocks were pooled from multiple random sites in both lungs. Specimens were postfixed in Zetterqvist's fixative, en bloc stained with uranyl acetate, dehydrated in ethanol, and embedded in Spurr's. Thick sections were obtained from all blocks and screened. Subsequent thin sections from five blocks were examined with a Phillips 301 or JEOL 100CX transmission electron microscope.

Morphometric ultrastructural data on three $140 \pm 2$ days $(0$ time), three 180 day (term), and four each 11 day PRN and $100 \% \mathrm{O}_{2}$ treated animals were determined as described by Bolender and colleagues (18-21) and more recently by Massaro et al. (22). Volume densities of the various alveolar wall components and type II organelles were determined according to the method of Weibel (23). Square lattice test systems were used to gather point and intersection counts from electron micrographs at final magnifications of approximately $\times 2,700$ and $\times 11,000$ 
(18). The ratio of coarse to fine points in the test systems was $1: 25$, and the length of one of two linear probes associated with each of the coarse and fine points was 2 and $0.4 \mathrm{~cm}$, respectively. To determine the volume density (fraction of cell volume) and surface-to-volume ratio, 10 each of type I cells, type II cells, interstitial cells, macrophages, and endothelial cells were photographed at random from five blocks per animal and enlarged to a final magnification of $\times 11,000$.

A one-way analysis of variance procedure was used to assess differences between the four groups for each variable. Inasmuch as many of the variables were calculated as percentages of a total, the arcsin square root transformation was used when it improved the homogeneity of variance assumption as measured by Hartley's F-max statistic $(24,24 a)$. For ratio variables, the log transform was used to stabilize variances. For both untransformed and transformed data values the one-way analysis of variance was followed by a comparison of group means with $t$ tests using the analysis of variance error term. Statistical significance is recorded by giving the actual $p$ value. For multiple comparison purposes, one should multiply the individual $t$ test $p$ value comparison by the number of comparisons of interest, i.e. use Bonferroni's inequality (25).

\section{RESULTS}

The influence of the various ventilatory strategies on the outcome of the 96-hour and 11-day study animals have been published (14). Although there were no group to group differ-

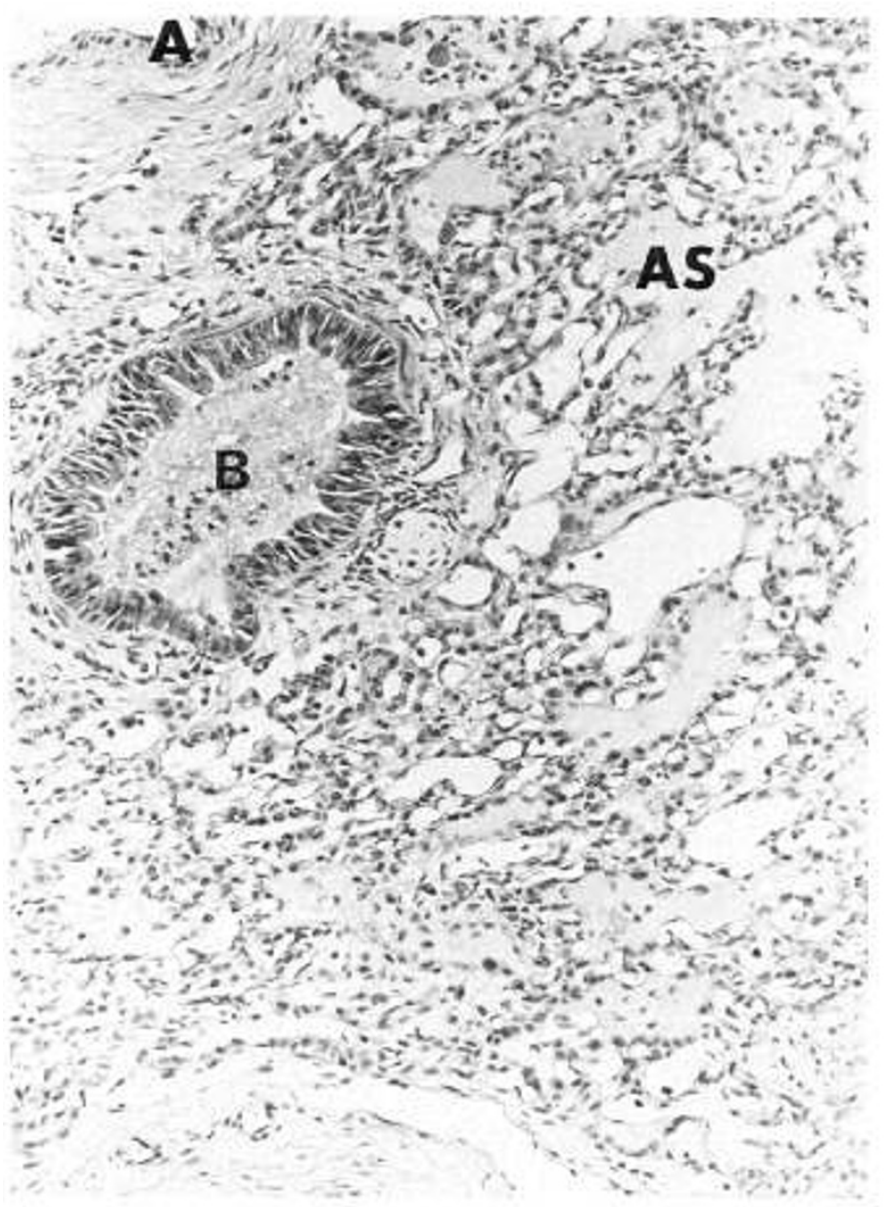

Fig. 5. A 4-day $100 \% \mathrm{O}_{2}$-treated specimen. Hyperplastic epithelium is evident in the small bronchus $(B)$. The surrounding saccules $(A S)$ are unevenly inflated and several contain edema and a few macrophages and PMN. $A$, pulmonary artery. Hematoxylin and eosin, $\times 150$.

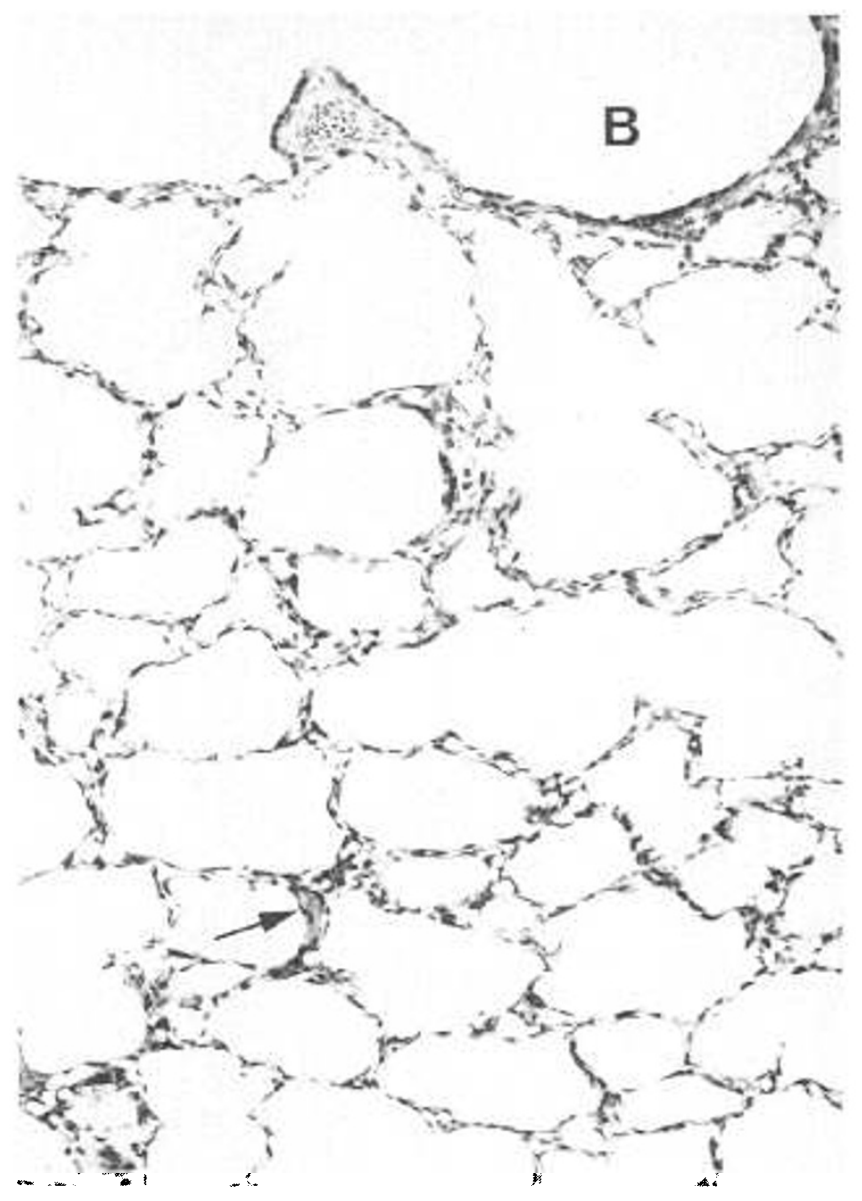

Fig. 6. A 4-day PRN $\mathrm{O}_{2}$-treated specimen. Evenly inflated saccules with minimal evidence of edema or hyaline membranes are depicted. A probable residual hyaline membrane is marked by the arrow. The small bronchus $(B)$ shows flattened cuboidal epithelium. Hematoxylin and eosin, $\times 150$.

ences in the type of injury, namely, PIE, the degree of involvement did differ. Samples remote from the PIE lesions were used for ultrastructural study.

Zero-time specimens from prematures not allowed to breathe showed thickened saccular walls and a cuboidal epithelial lining, features consistent with a late saccular phase of development. Ultrastructurally, well-glycogenated type II cells with few, if any, lamellar bodies were evident. The interstitium was mesenchymal in appearance, with large quantities of ground substance and few cells. The endothelium was plump and contained abundant organelles. Hyaline membranes and edema were not present.

Light microscopic findings from all animals $24 \leq \mathrm{h}$ old showed typical HMD. Extensive saccular atelectasis with resulting ectasia of noncartilaginous airways was the dominant finding, resulting in marked thinning and focal loss of the airway epithelium (Fig. 1). Partially opened or open saccules contained edema and/or early hyaline membrane formation. Hyaline membranes were prominently seen at respiratory bronchiolar and alveolar duct sites. They did not stain with PTAH. These findings were comparable in both $100 \% \mathrm{O}_{2}$ and PRN-treated animals. In the 24-h $100 \% \mathrm{O}_{2}$-treated animals interstitial pulmonary emphysema and pseudocyst formation with accompanying hemorrhage were consistently seen, lesions not seen in the $1 / 2$ or one-day PRN animals. Electron microscopic findings were comparable in both treatment groups at these study periods. Saccules contained edema and/or proteinaceous hyaline membranes (Figs. 2 and 3). Fibrin strands were not seen ultrastructurally. Type II cells had negli- 
gible numbers of lamellar inclusion bodies and type I cells were edematous and focally lost. The endothelium appeared normal, whereas the interstitium contained abundant cells.

The 48-h specimens from both $100 \% \mathrm{O}_{2}$ and PRN treatment groups showed HMD and could not be distinguished light microscopically. Interstitial pulmonary emphysema was seen in $80 \%$ of the PRN group and in $60 \%$ of the $100 \%$-treated animals. Ultrastructurally, focal type I epithelial loss was still evident in both study groups. In the $100 \%$ study animals, focal endothelial edema and necrosis were present (Fig. 4).

Striking differences in the two treatment groups were present in the 3- to 6-day study animals. The $100 \% \mathrm{O}_{2}$-treated group showed focal sites of saccular edema but few hyaline membranes (Fig. 5), whereas the PRN oxygen group had no evidence of persistent HMD or an ongoing permeability leak (Fig. 6). Interstital emphysema was seen in one-third of the $100 \% \mathrm{O}_{2}$-treated animals, but in only two of the 18 PRN oxygen-treated group. Of the $100 \%$ oxygen-exposed animals in the 3- to 6-day group, more than $40 \%$ had epithelial necrosis and hyperplastic/metaplastic reparative changes in small airways. The only lesion in the PRN treatment group was the variable presence of hemorrhage at the junction of some bronchioles and their immediately adjacent saccular walls, an area susceptible to shear force injury. Electron microscopically, the changes were quite disparate between the two study groups. Epithelial loss, hyaline membranes and/or saccular edema, interstitial edema and free red blood cells, and endothelial edema and/or necrosis were present in the

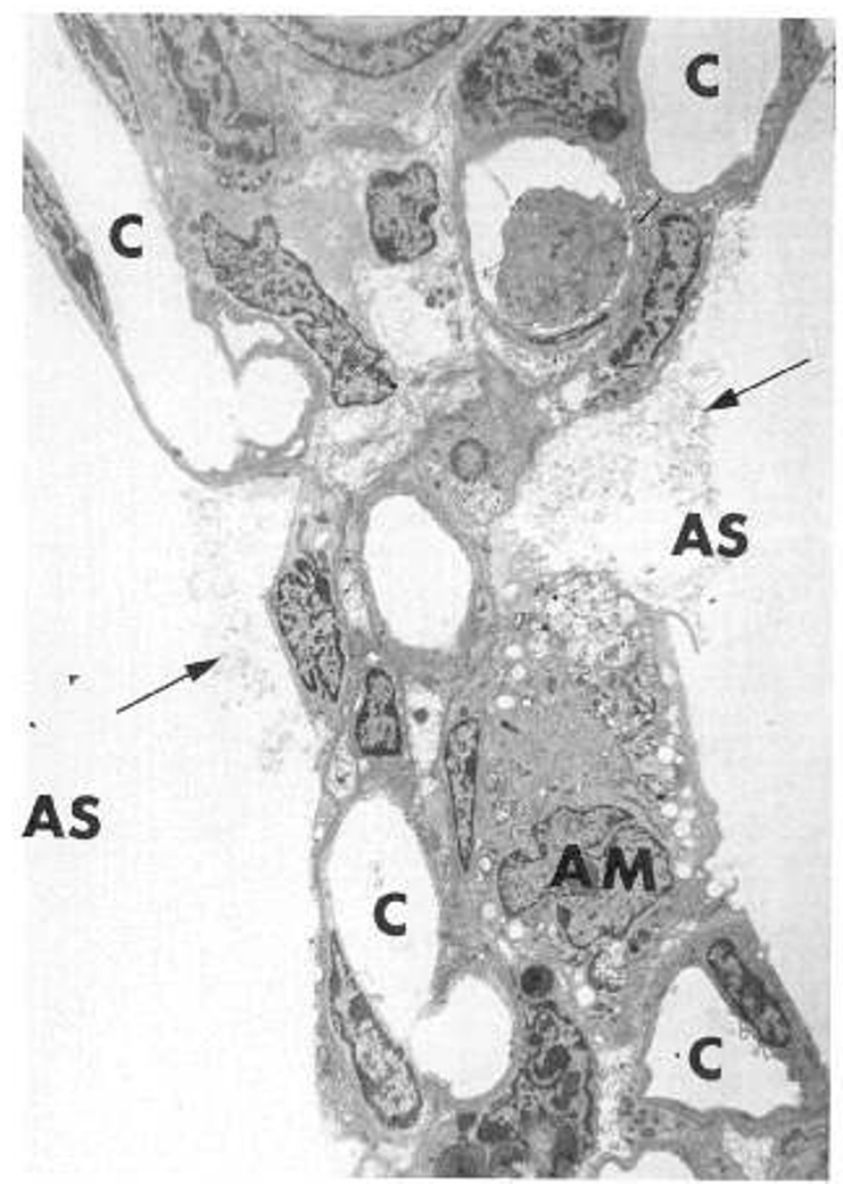

Fig. 7. A 4-day $\mathrm{PRN}_{2}$-treated specimen. Remnants of hyaline membrane material (?) intermixed with lamellar-like bodies (arrows) are seen in the "niches" of the saccular spaces $(A S)$. Many capillaries $(C)$ are evident. An alveolar macrophage $(A M)$ is filled with secondary lysosomes in which the phagocytosed material resembles that within the "niches." Lead citrate and uranyl acetate, $\times 2400$.

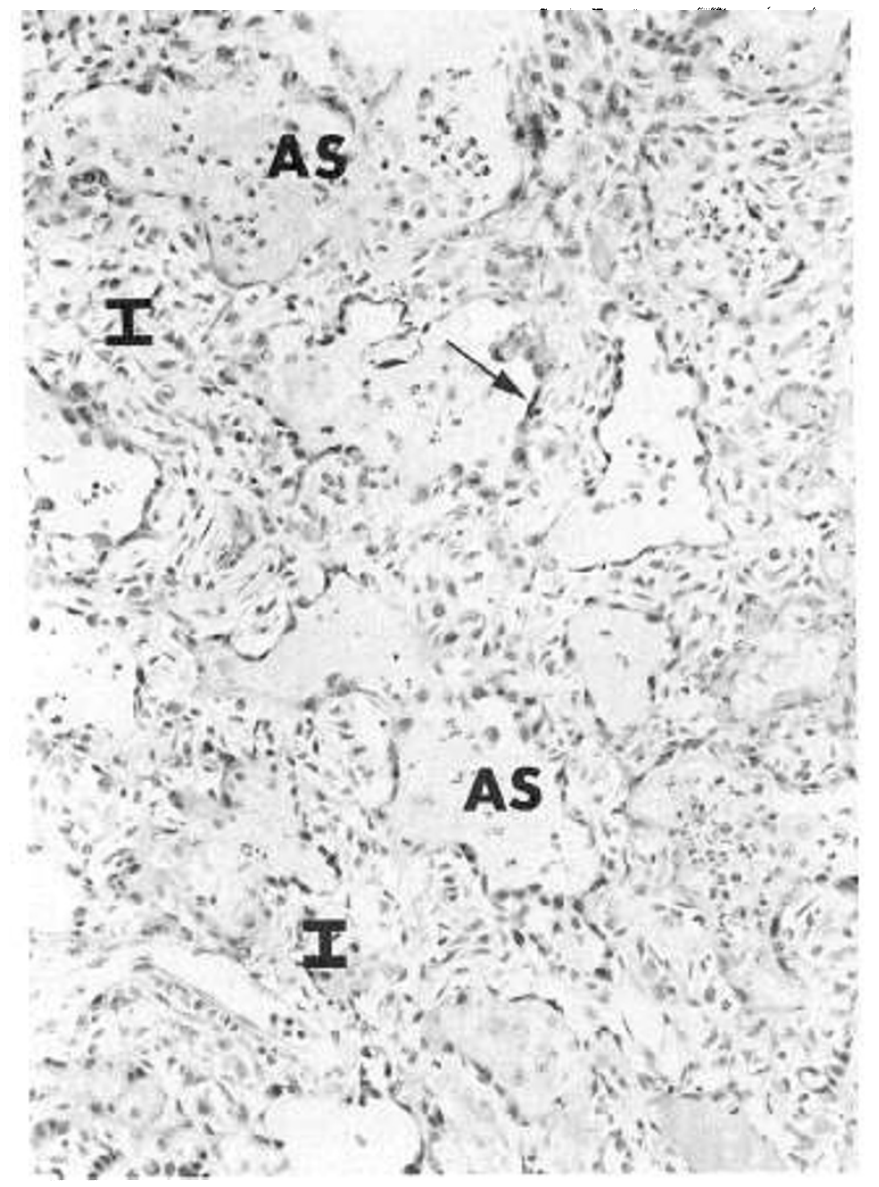

Fig. 8. A 9-day $100 \% \mathrm{O}_{2}$-treated specimen. The saccular walls $(I)$ are thickened and contain increased cells and connective tissue elements (confirmed on connective tissue stain). Epithelial type II hyperplasia is evident (arrow). The air spaces ( $A S$ ) are filled with edema and scattered PMN and macrophages. The findings are consistent with mixed exudative-reparative lesion of diffuse alveolar damage. Hematoxylin and eosin, $\times 160$.

$100 \% \mathrm{O}_{2}$-treated animals, whereas the PRN-treated group showed focal type I epithelial edema, some aggregates of free surfactant material or edema in saccules, and only rare foci of hyaline membrane material (Fig. 7). The alveolar type II cells in both groups contained abundant lamellar inclusion bodies.

The 100\%-treated animals in the 7-to $11+$-day study showed stage 3 BPD histopathological changes (4). Focal hemorrhages and alveolar edema were present, but only rare hyaline membranes. Positive staining for fibrin strands in the edema fluid was seen in the PTAH preparations. Increased connective tissue deposition, found predominantly in the saccular walls, was easily identified with Masson's connective tissue/elastica stain by 9 days (Fig. 8). Peribronchial/iolar fibrosis that extended into the surrounding saccular areas was seen in this group (Fig. 9), but no medial hypertrophy or subintimal fibrosis was noted in the arteries accompanying the airways. The only light microscopic changes in the PRN oxygen-treated baboons were focal hemorrhages in $50 \%$ of the animals and pseudocysts, small in size and number, in two animals. In none of the PRN oxygen-treated animals was abnormal connective tissue deposition evident.

Ultrastructurally, in the $100 \% \mathrm{O}_{2}$-treated group, endothelial vacuolization and necrosis were frequently present. Increased numbers of pericytes could be seen surrounding corner vessels and some capillaries. Edema and/or increased mononuclear cells and fibroblasts were evident in the intersitium. The epithelium of $100 \% \mathrm{O}_{2}$-treated animals showed sites of type II hyperplasia 


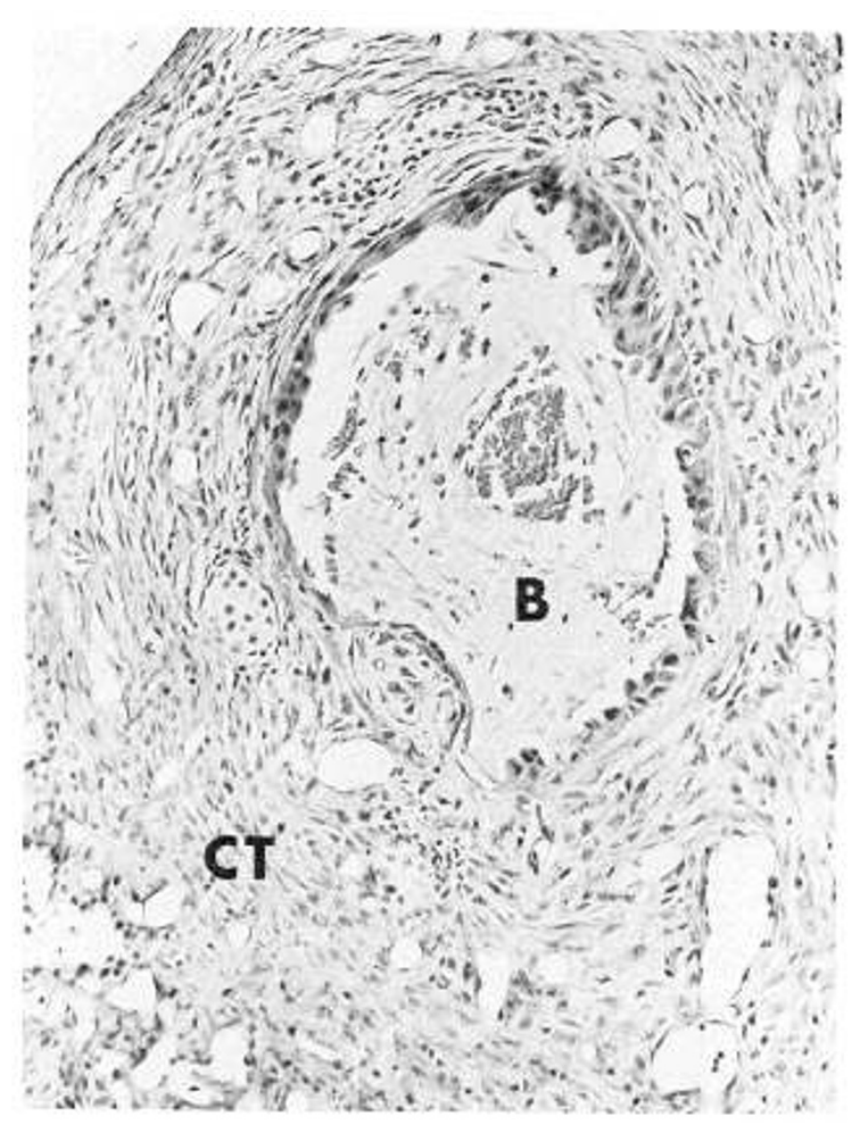

Fig. 9. A 11-day $100 \% \mathrm{O}_{2}$-treated specimen. The bronchus $(B)$ has a plug of RBC and protein and the epithelial lining shows metaplastic cellular changes. The peribronchial fibrosis is depicted by a circular band of connective tissue $(C T)$. Hematoxylin and eosin, $\times 150$.

with numerous mitotic figures. Occasionally, dark staining type II cells alternated with adjoining lighter ones indicating ongoing necrosis. Numerous lamellar bodies were in the type II epithelium and abundant free lamellar bodies were in the saccular spaces. Multiple macrophages, focal hemorrhages, fibrin, and edema fluid were present in the alveolar spaces.

In the $11+$-day $100 \% \mathrm{O}_{2}$ specimens (14 and 17 days), lipidladen macrophages were evident, secondary to obstructive airway lesions. Hyperplastic/metaplastic changes in airway epithelium, interstitial fibrosis (Fig. 10), and a prominent inflation pattern of alternating atelectasis and overinflation were evident (Fig. 11). PRN oxygen specimens consistently showed a lack of epithelial or endothelial injury/necrosis. Type II cells showed numerous lamellar bodies and alveolar macrophages were evident within saccular spaces. The only significant pathology in this group was focal sites of intraalveolar hemorrhage. The results of the morphological findings of the hyperoxic treated animals are displayed in a form adapted from Katzenstein and Askin (3) for DAD in Figure 12.

The nuclear numerical density data of the 11-day PRN and $100 \%$ oxygen-treated animals and the 140 - ( 0 time) and 180-day (term) day animals are displayed in Tables 2 and 3 . The number of type I epithelial cells was comparable in the 140-day and term animals. Those of 11-day PRN and $100 \% \mathrm{O}_{2}$ animals were decreased in number, the latter at near significant levels when compared to 140-day and term controls. Type II cells in both 11-day groups were increased in number when compared with 0 time and term animals, with the 11 -day $100 \% \mathrm{O}_{2}$ group value was significantly higher than that of the term animals $(p<0.05)$. The type II/I ratio (Table 4 ) in the $100 \% \mathrm{O}_{2}$-treated 11-day animals was significantly different from 0 time control and term values $(p<0.05)$.
The number of endothelial cells was decreased and comparable in the 140- and 11-day hyperoxic-injured animals. The 11-day $100 \% \mathrm{O}_{2}$ value was significantly decreased $(p<0.04)$ when compared to the 11-day PRN controls, suggesting a failure of vascular development in the former. The total number of interstitial cells was significantly greater in number in the 140-day premature baboon specimens when compared with the term and 11 -day PRN groups ( $p<0.04$ and $p<0.004$, respectively). The 11-day $100 \% \mathrm{O}_{2}$ group had more interstitial cells than the 11day PRN group, but only at a $p<0.07$ significance level. Of interest, the volume density data (Tables 5 and 6) showed that the total interstitial compartment in the 11-day $100 \% \mathrm{O}_{2}$ animals was significantly larger when compared to the other groups, due primarily to an increase in edema (noncellular material). The capillary lumina of ten and both 11-day study groups were significantly larger $(p<0.01)$ than those of the 140-day specimens.

Within the alveolar space compartment, macrophages accumulated with time and were significantly increased in both 11day groups $(p<0.05)$ when compared to 0 time controls. Minimal but significant $(p<0.05)$ numbers of PMN were found in the 11-day hyperoxic-treated animals and this group also had significantly increased amounts of fibrin and edema when compared to all other groups.

No significant differences were seen in the intracellular volumes of the four alveolar wall cell types among the four groups (data not shown).

\section{DISCUSSION}

There are several unique pathological features in bronchopulmonary dysplasia; an alternating pattern of overinflation/atelec-

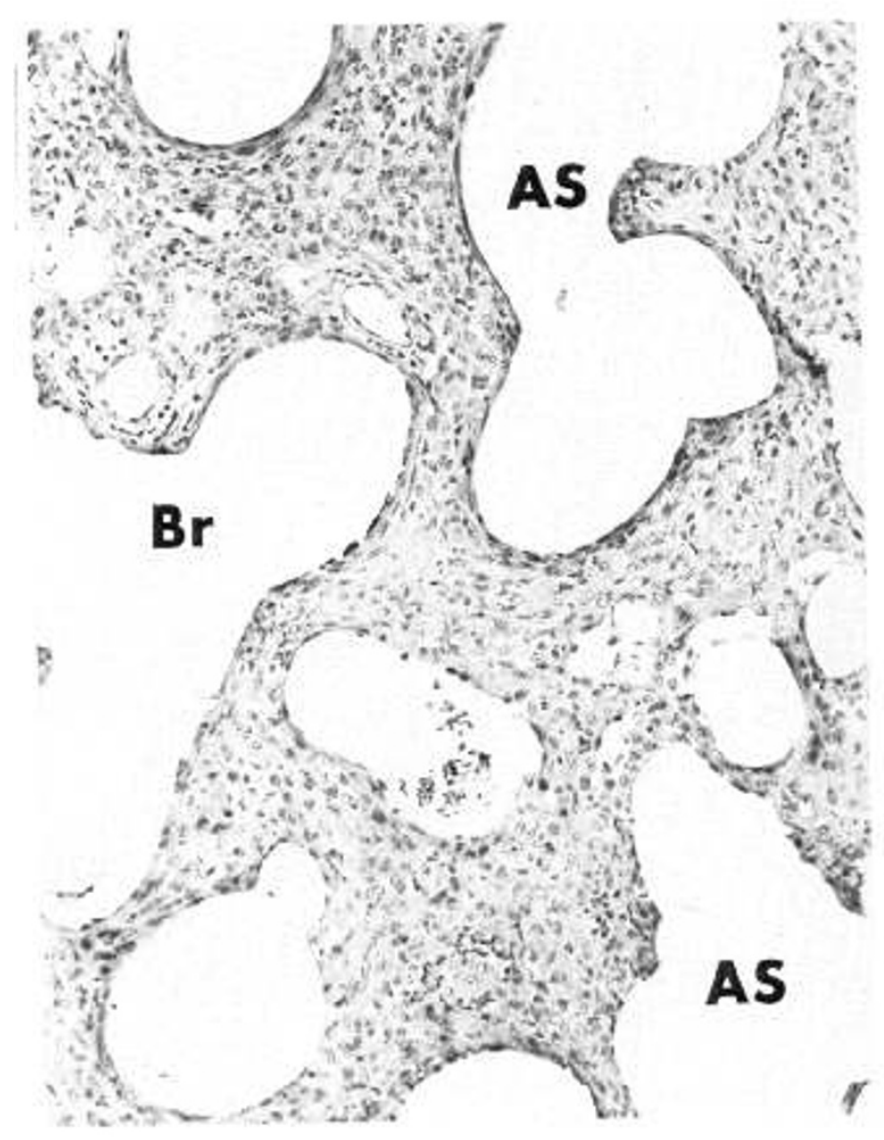

Fig. 10. A 17-day $100 \% \mathrm{O}_{2}$-treated specimen. Prominent fibroplasia of the "remodeled" distal air spaces $(A S)$ is evident. Collagen stains revealed significant collagen fiber deposition. $\mathrm{Br}$, bronchiole. Hematoxylin and eosin, $\times 150$. 


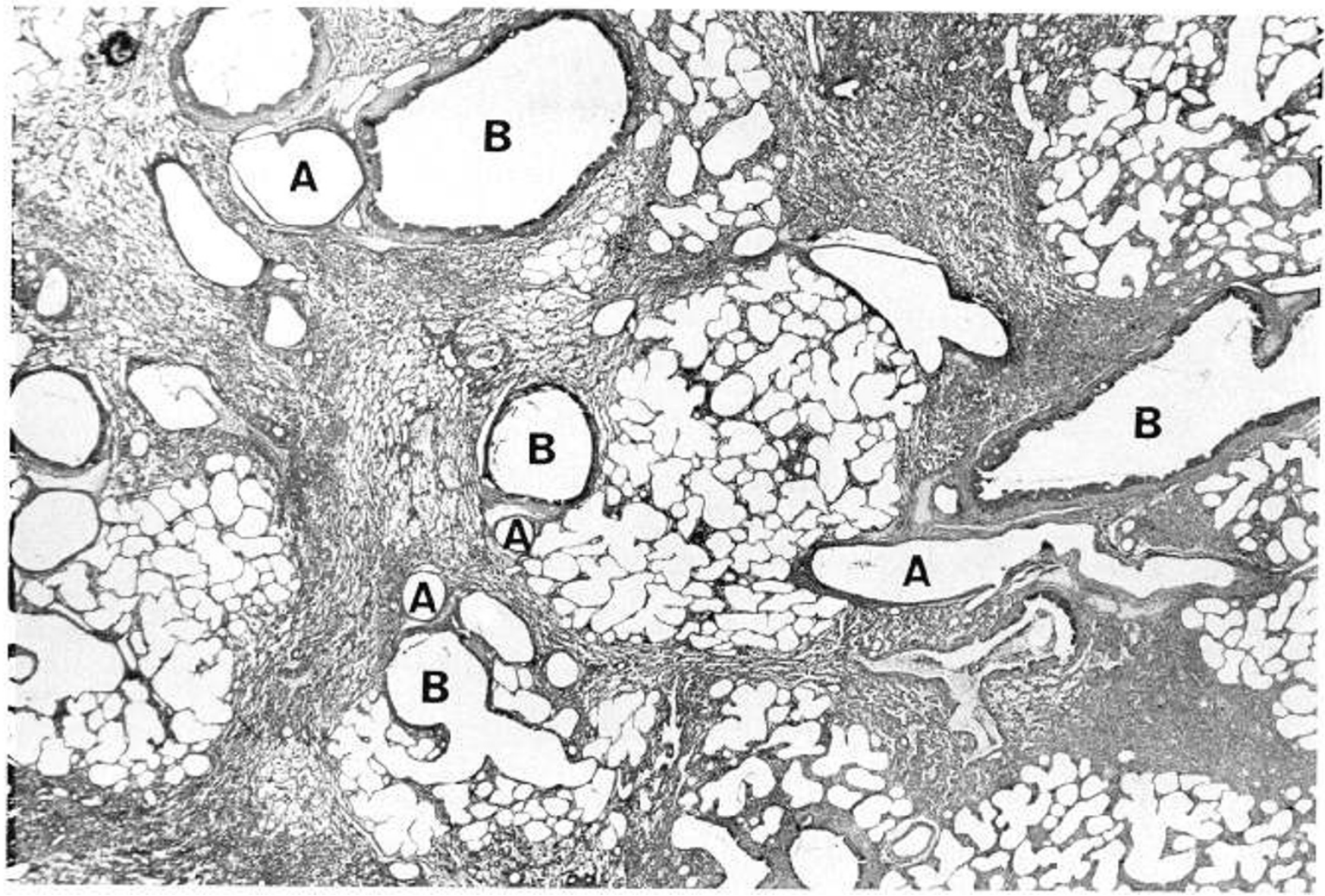

Fig. 11. A 17-day $100 \% \mathrm{O}_{2}$-treated specimen. The altered inflation pattern, seen consistently in the $7-11+$ day specimens, is very exaggerated by 17 days. Sites of overinflation with "simplifcation" of the involved saccular walls alternates with atelectatic and/or fibrotic bands. $B$, bronchus; A, pulmonary artery. Hematoxylin and eosin, $\times 20$.

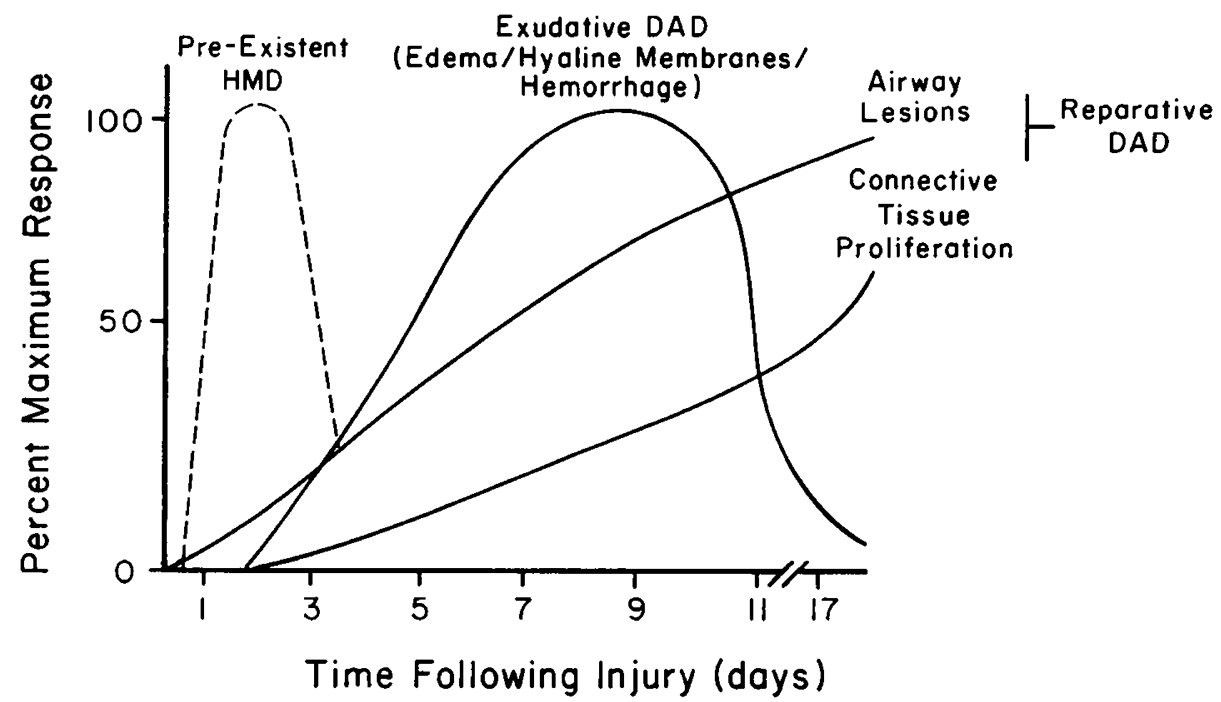

Fig. 12. Bronchopulmonary dysplasia. The histopathologic findings are plotted over time to depict the points of maximum response [after Katzenstein and Askin (3)].

tasis, injury/reparative findings in airways, and a high incidence of interstitial pulmonary emphysema. However, the findings of edema, hyaline membranes, and focal hemorrhages with ensuing fibrosis are comparable to the exudative and reparative phases of diffuse alveolar damage seen in patients with the adult respiratory distress syndrome $(3,5-7)$.
The appearance and evolution of the edema and hyaline membranes in a premature lung treated with oxygen are particularly difficult to assess as those two features are also primary findings in HMD (26-28). It is unlikely that prematures would have an intact antioxidant enzyme system at delivery $(29,30)$ so susceptibility to oxygen damage would be expected. Endothelial 
damage was evident in our hyperoxic-injured specimens by 48 h. However, at 3-4 days of age, it cannot be resolved with light microscopy if the hyaline membranes and edema are retained residue of HMD that has not yet resolved or represent "new" exudate secondary to a permeability leak or result from a combination of two processes. Regardless, the findings at this stage are consistent with our previous observations that clinical recovery from HMD is hampered by continued exposure to $100 \%$ oxygen (12). The hyaline membranes seen in the first few days in the premature baboon do not stain for fibrin, unlike those of the oxygen-injured adult baboon with exudative diffuse alveolar damage during the first 6 days postinjury. Data are variable concerning the presence of fibrin in the hyaline membranes of human premature infants with HMD (27). Even when the premature baboon develops exudative $\mathrm{DAD}$, fibrin-containing hyaline membranes are not as prominent as in the adult. Alveolar edema is the more predominant finding in which a few positivestaining fibrin strands can be seen. The precise composition of the hyaline membranes in infants 1-3 days old with uncomplicated HMD needs further study.

If one compares adult and premature baboons after identical 6 -day periods of $100 \%$ oxygen exposure, the exudative response in the premature lung is greatly diminished when compared to the adult lung $(8,9)$. It is extremely difficult to support adult baboon in $100 \%$ oxygen for periods longer than seven days because of the development of severe edema and respiratory failure $(8,9)$; whereas, premature animals with comparable oxygen exposure and supportive care can be successfully maintained for a period of 17 days (10). This blunted exudative response with fewer fibrin-containing hyaline membranes may explain why the fibrotic response is more evident in the saccular wall than in the saccular space of 11 -day $100 \% \mathrm{O}_{2}$-treated premature infants. Hyaline membranes in adult patients with ARDS have more abundant fibrin that serves as the scaffold for intramural organization of the exudate within the alveolar space (3). The paucity of characteristically stained fibrin in the premature animals may be related to immaturity of their coagulation system. Alternatively, fibrin may be present but not staining because of differences in polymerization. Better methods for identifying fibrinogen/fibrin will be of value in further defining this issue.

The blunted exudative response to hyperoxic injury in newborn lungs was noted by Hellstrom and Nergardh in 1965 (31) who exposed newborn mice to $100 \%$ oxygen for 5 to 25 days. They noted the lack of an exudative lesion and described a

Table 2. Nuclear numerical density of alveolar wall cells expressed as \% of total*

\begin{tabular}{lrrrr}
\hline & & & \multicolumn{1}{c}{$\begin{array}{c}11 \mathrm{Day} \\
\text { PRN }\end{array}$} & \multicolumn{1}{c}{$\begin{array}{c}11 \text { Day } \\
100 \% \mathrm{O}_{2}\end{array}$} \\
\hline Type I & $4.5 \pm 1.4$ & $5.3 \pm 1.0$ & $2.5 \pm 1.0$ & $1.7 \pm 0.4$ \\
Type II & $14.3 \pm 4.8$ & $13.7 \pm 1.9$ & $25.0 \pm 4.9$ & $26.9 \pm 3.9$ \\
$\begin{array}{c}\text { Endo- } \\
\text { thelial }\end{array}$ & $16.8 \pm 4.3$ & $33.0 \pm 3.7$ & $31.9 \pm 3.0$ & $18.8 \pm 4.8$ \\
Interstitial & $64.4 \pm 8.7$ & $48.1 \pm 5.0$ & $40.6 \pm 2.6$ & $52.6 \pm 1.7$ \\
\hline
\end{tabular}

${ }^{*} p$ values for intergroup comparisons in Table 3. pattern of emphysema and patchy atelectasis, and in older animals, connective tissue proliferation and hemorrhages. It has been our experience that if prematures survive the first $48 \mathrm{~h}$ without severe pulmonary airleak problems, they can usually be successfully managed until a second high mortality peak at 9-11 days at which time pulmonary edema and hemorrhage become a major complicating factor superimposed on the evolving bronchopulmonary dysplasia process.

The peculiar inflation pattern that manifests itself in premature baboon as early as 7-9 days does not have a true counterpart in adult DAD. It is tempting to attribute this difference in the infant to a combination of surfactant deficiency, airways with small diameters plus frequent intraluminal obstructive material and/ or epithelial reparative changes in a lung with a lack of pores of Kohn and other collateral ventilatory routes. However, comparable alternating inflation and atelectasis patterns have been reported in 1-month-old rats treated with $100 \%$ oxygen for $2 \mathrm{wk}$ (32), newborn mice treated with $100 \%$ oxygen for 3 wk (33), adult mice treated with $100 \%$ oxygen for 5-25 days (31), adult

Table 4. Ratio of type II/type I cells

\begin{tabular}{lc}
\hline & Type II/I ratio \\
\hline 140 day & $3.9 \pm 1.5$ \\
Term & $2.8 \pm 0.5$ \\
11 day PRN & $16.6 \pm 6.9^{*}$ \\
11 day $100 \% \mathrm{O}_{2}$ & $20.1 \pm 6.3 \dagger, \dot{\ddagger}$ \\
\hline
\end{tabular}

${ }^{*} p<0.09$ by analysis of variance $t$ test compared to 140 day and term.

$\dagger p<0.05$ by analysis of variance $t$ test compared to 140 day.

$\ddagger p<0.05$ by analysis of variance $t$ test compared to term.

Table 5. Volume densities of alveolar components*_volume density $\%$

\begin{tabular}{|c|c|c|c|c|}
\hline & 140 Days & Term & 11-Day PRN & $\begin{array}{c}\text { 11-Day } \\
100 \% \mathrm{O}_{2}\end{array}$ \\
\hline \multicolumn{5}{|l|}{ Alveolar epithelium } \\
\hline Types I and II & $13.85 \pm 0.51$ & $6.46 \pm 1.56$ & $13.49 \pm 0.97$ & $19.46 \pm 2.47$ \\
\hline Type I & $1.98 \pm 0.76$ & $1.51 \pm 0.35$ & $1.43 \pm 0.54$ & $0.85 \pm 0.16$ \\
\hline Type II & $11.79 \pm 1.19$ & $4.94 \pm 1.26$ & $12.05 \pm 1.01$ & $18.60 \pm 2.47$ \\
\hline \multicolumn{5}{|l|}{ Vascular } \\
\hline Endothelium & $4.45 \pm 1.15$ & $5.06 \pm 1.05$ & $6.53 \pm 0.98$ & $4.82 \pm 0.94$ \\
\hline Lumen & $3.03 \pm 0.25$ & $9.26 \pm 1.61$ & $12.53 \pm 1.53$ & $8.12 \pm 1.73$ \\
\hline \multicolumn{5}{|l|}{ Interstitial } \\
\hline Total & $25.13 \pm 1.97$ & $12.58 \pm 3.37$ & $20.00 \pm 3.32$ & $35.91 \pm 2.92$ \\
\hline Cellular & $10.37 \pm 1.32$ & $5.52 \pm 1.52$ & $8.69 \pm 3.08$ & $12.43 \pm 5.37$ \\
\hline Noncellular & $13.92 \pm 2.82$ & $6.26 \pm 2.76$ & $10.98 \pm 1.27$ & $22.25 \pm 3.41$ \\
\hline Connective tissue & $0.95 \pm 0.41$ & $0.81 \pm 0.43$ & $0.35 \pm 0.14$ & $1.67 \pm 0.65$ \\
\hline \multicolumn{5}{|l|}{ Alveolar space } \\
\hline Total & $53.94 \pm 3.03$ & $66.49 \pm 6.78$ & $47.21 \pm 5.86$ & $31.29 \pm 3.75$ \\
\hline $\mathrm{F} \dagger / \mathrm{HM} / \mathrm{E} / \mathrm{S}$ & $0.49 \pm 0.20$ & $0.28 \pm 0.14$ & $0.81 \pm 0.36$ & $5.47 \pm 1.83$ \\
\hline Hemorrhage & $0.04 \pm 0.03$ & $0.09 \pm 0.07$ & $2.21 \pm 1.35$ & $2.90 \pm 2.03$ \\
\hline Macrophages & $0.03 \pm 0.02$ & $0.45 \pm 0.37$ & $1.22 \pm 0.72$ & $1.33 \pm 0.63$ \\
\hline PMN & $0.00 \pm 0.00$ & $0.00 \pm 0.00$ & $0.01 \pm 0.01$ & $0.41 \pm 0.30$ \\
\hline
\end{tabular}
etc.)

Table 3. Intergroup comparisons ( $p$ value)* (\% total nuclear numerical density values)

\begin{tabular}{lcccc}
\hline & Type I & Type II & Endothelial & Interstitial \\
\hline 140 day $v$ s term & 0.593 & 0.918 & 0.026 & 0.041 \\
140 day s 11 day PRN & 0.155 & 0.108 & 0.026 & 0.004 \\
140 day $v$ 11 day $100 \% \mathrm{O}_{2}$ & 0.059 & 0.064 & 0.736 & 0.099 \\
Term $v$ s 11 day $\mathrm{PRN}$ & 0.059 & 0.089 & 0.856 & 0.275 \\
Term s 11 day $100 \% \mathrm{O}_{2}$ & 0.022 & 0.053 & 0.035 & 0.502 \\
11 day PRN s 11 day $100 \% \mathrm{O}_{2}$ & 0.540 & 0.743 & 0.035 & 0.073 \\
\hline
\end{tabular}

* These are nonadjusted $p$ values for multiple comparisons from the analysis variance. For Bonferroni's adjustment use $0.05 / 6=0.0083(25)$. 


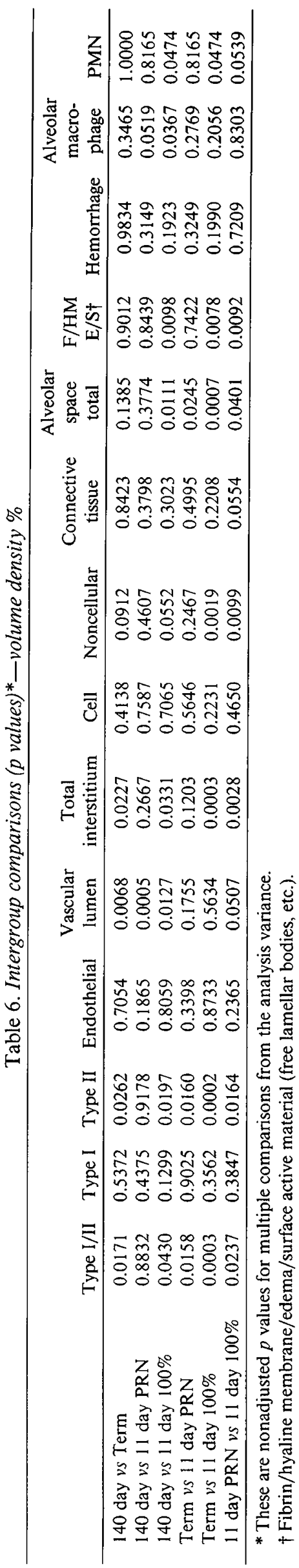

rats treated with $100 \%$ oxygen for 6 wk (34), and adult dogs treated with $60 \%$ oxygen for 33 days (35). Therefore, the notion that only premature lungs are at risk of developing this peculiar lesion is negated.

The "alveolitis" of ARDS has received much study $(36,37)$. Although no mention of neutrophils in the alveolar exudate of exudative DAD was made in the early reports, several investigators have noted their presence in abnormal numbers in bronchoalveolar lavage specimens $(36,37)$. When compared to an adult baboon treated with $100 \%$ oxygen for $5-7$ days $(8,9)$, the premature baboon (with comparable oxygen exposure) has a remarkable paucity of neutrophils within the alveolar exudate at 3 to 6 days. The relative lack of both neutrophils and alveolar macrophages, important sources of free radicals and/or mediators, during the early days of oxygen exposure may partially explain the "modified" evolution of diffuse alveolar damage in the premature. At 9-11 days, neutrophils can be seen, but since bacterial cultures were not obtained, a superimposed bacterial bronchopneumonia cannot be excluded. Data from the adult baboon with oxygen injury clearly indicate that animals with numerous PMN invariably have superimposed infections with positive polymicrobial cultures and elevated bacterial indices (38). Another feature that may partially explain the relative lack of an "alveolitis" in the premature baboon is the bacterial sterility of the premature's oropharynx, lung, and gastrointestinal tract at birth and the use of antibiotics. The prematures only with time become colonized, a situation very unlike the adult baboon or human. The role of infection in augmenting or accelerating lung injury and repair needs extensive study. The presence of PMN may herald the presence of colonization, infection, and/ or ensuing neutrophil-induced lung injury activity. This issue has not been adquately addressed in either adult or premature models of chronic lung injury.

The morphometric data obtained from the oxygen-injured 11day animals mirror many of the well-described alveolar wall findings in oxygen toxicity studies of patients and several animal models (39-44). When compared to 11-day PRN animals, the interstitium of 11 -day $100 \% \mathrm{O}_{2}$ animals shows proliferative changes with an increase in both cells and edema. However, the major difference between these two groups is the significant loss of endothelial cells in the $100 \% \mathrm{O}_{2}$ group. Although type I cells are being extensively replaced by type II cells in the 11-day $100 \%$ $\mathrm{O}_{2}$ animals, this is also occurring in the 11-day PRN animals, so the "epithelial hyperplasia" may be a response of a premature lung that is exposed to the extrauterine environment. In hyperoxic-treated animals the impact of the endothelial loss and the interstitial reparative response on ongoing lung growth and differentiation is not known at this time.

In summary, there are overlapping histological lesions that can be defined as exudative and/or reparative DAD in the premature lung exposed to hyperoxia. However, when contrasted to DAD in adult lung, there are temporal and qualitative differences in the extent of the response over time when compared to adult models of oxygen-induced lung injury. In addition, the altered inflation pattern, airway changes, and lack of structural lung maturity permit exaggerated histological responses in the infant lung that potentially may interfere with the immature lung's "program" for normal growth and development.

Acknowledgments. The authors thank the baby baboon ICU staff for their support. Special recognition and thanks to Pathology technicians, Vicki Winter, Linda Buchanan, Gwynne Canales, and Misako Ankrum, for the long hours spent doing the labor intensive point counts and intersects. The expert secretarial skills and assistance of Ginny Wolfe are gratefully acknowledged.

\section{REFERENCES}

1. Winternitz MC 1920 Collected Studies on the Pathology of War Gas Poisoning Yale University Press, New Haven, CT, pp 1-165 
2. Katzenstein AA, Bloor CM, Leibow AA 1976 Diffuse alveolar damage-the role of oxygen, shock and related factors. A review. Am J Pathol 85:210228

3. Katzenstein AA, Askin FB 1982 Diffuse alveolar damage. In: Surgical Pathology of Non-Neoplastic Lung Disease. Major Problems in Pathology, Vol. 13. Diffuse Alveolar Damage. W.B. Saunders Company, Philadelphia, pp 942

4. Northway WH, Jr, Rosan RC, Porter DY 1967 Pulmonary disease following respirator therapy of hyaline-membrane disease. N Engl J Med 276:357-368

5. Soloway HB, Castillo Y, Martin AM 1968 Adult hyaline membrane disease: Relationship to oxygen therapy. Ann Surg 168:937-945

6. Lamy M, Fallat RJ, Koeniger E, Dietrich H-P, Ratliff JL, Eberhart RC, Tucker HJ, Hill JD 1976 Pathologic features and mechanisms of hypoxemia in adult respiratory distress syndrome. Am Rev Respir Dis 114:267-284

7. Pratt PC, Vollmer RT, Shelburne JE, Crapo JD 1979 Pulmonary morphology in a multihospital collaborative extracorporeal membrane oxygenation project. I. Light microscopy. Am J Pathol 95:191-214

8. de los Santos R, Coalson JJ, Holcomb JR, Johanson WG Jr 1985 Hyperoxia exposure in mechanically ventilated primates with and without previous lung injury. Exp Lung Res 9:255-275

9. de los Santos E, Seidenfeld JJ, Anzueto A, Collins JF, Coalson JJ, Johanson WG Jr, Peters JI 1987 One hundred percent oxygen lung injury and infection in adult baboons. Am Rev Respir Dis 136:657-661

10. Coalson JJ, Kuehl TJ, Escobedo MB, Hilliard JL, Smith F, Meredith K, Null DM Jr, Walsh W. Johnson D, Robotham JL 1982 A baboon model of bronchopulmonary dysplasia: II. Pathologic features. Exp Mol Pathol $37: 335-350$

11. deLemos RA, Coalson JJ, Null DM Jr, Ackerman NB, Escobedo MB, Robotham JL, Kuehl TJ 1987 Ventilatory management of infant baboons with hyaline membrane disease: the use of high frequency ventilation. Pediatr Res 21:594-602

12. deLemos RA, Coalson JJ, Gerstmann DR, Kuehl TJ, Null DM Jr 1987 Oxygen toxicity in the premature baboon with hyaline membrane disease. Am Rev Respir Dis 136:677-681

13. Bell RE, Kuehl TJ, Coalson JJ, Ackerman NB, Null DM Jr, Escobedo MB, Yoder BA, Cornish JD, Nalle L, Sharin RM, Cipriani CA, Montes M, Robotham JL, deLemos RA 1984 High frequency ventilation compared to conventional positive pressure ventilation in the treatment of hyaline membrane disease in primates. Crit Care Med 12:764-768

14. Gertsmann DR, deLemos RA, Coalson JJ, Clark R, Wiswell TE, Winter DC, Kuehl TJ, Meredith KS, Null DM Jr The influence of ventilatory technique on pulmonary baroinjury in baboon hyaline membrane disease. Pediatr Pulmonol (in press)

15. Coalson JJ 1983 A simple method of lung perfusion fixation. Anat Rec 205:233-238

16. Karnovsky MJ 1965 A formaldehyde-glutaraldehyde fixative of high osmolality for use in electron microscopy. J Cell Biol 27:137A-138A

17. Scherle W $1970 \mathrm{~A}$ simple method for volumetry on organs in quantitative stereology. Mikroskopie 26:57-60

18. Bolender RP 1979 Surface area ratios I. A sterological method for estimating average cell changes in membrane surface areas. Anat Rec 194:511-522

19. Bertram JF, Bolender RP 1983 Estimating the frequencies of parenchymal cells in the goat lung. Acta Stereol 2:273-276

20. Bolender RP 1983 Methods for decreasing the statistical variance of stereological estimates. Anat Rec 207:89-106

21. Bolender RP, Pentcheff ND 1985 Computer Programs for Biological Sterology PCS Systems I. Washington Research Foundation, Seattle, WA

22. Massaro GD, McCoy L, Massaro D 1986 Hyperoxia reversibly suppresses development of bronchiolar epithelium. Am J Physiol 251:1045-1050

23. Weibel ER 1979 Stereological techniques for electron microscopic morphom- etry In: Sterological Methods. Practical Methods for Biology and Morphometry, Vol 1, Academic Press, New York, pp 109-122

24. Zar JH 1974 Biostatistical Analysis. Prentice-Hall, Englewood Cliffs, NJ, pp $130-150,182-189$

24a. Zar JH 1974 Data transformation. In: Biostatistical Analysis. Prentice-Hall, Englewood Cliffs, NJ, pp 182-189

25. Miller RG Jr 1981 Simultaneous Statistical Inference, 2nd ed. Springer-Verlag, New York, p 62

26. Tra-Dinh-De, Anderson G 1953 Hyaline-like membranes associated with disease of the newborn lungs: a recent review of the literature. Obstet Gynecol Surv 8:1-44

27. Lauweryns JM 1970 "Hyaline membrane disease" in newborn infants. Macroscopic, radiographic, and light and electron microscopic studies. Hum Pathol 1:175-204

28. Finlay-Jones JM, Papadimitriou JN, Barter RA 1974 Pulmonary hyaline membrane: light and electron microscopic study of the early stage. J Pathol 112:117-124

29. Frank L 1985 Effects of oxygen on the newborn. Fed Proc 44:2328-2334

30. Autor AP, Frank L, Roberts RJ 1976 Developmental characteristics of pulmonary superoxide dismutase: relationship to idiopathic respiratory distress syndrome. Pediatr Res 10:154-158

31. Hellstrom B, Nergardh A 1965 The effect of high oxygen concentrations and hypothermia on the lung of the newborn mouse. Acta Paediat Scand 54:457466

32. Brooksby GA, Dennis RL, Staley RW 1966 Effects of continuous exposure of rats to $100 \%$ oxygen at $450 \mathrm{mmHg}$ for 64 days. Aerospace Med 37:243-246

33. Bonikos DS, Bensch KG, Northway WH 1976 Oxygen toxicity in the newborn. Am J Pathol 85:623-635

34. Tierney DF, Ayers L, Kasuyama RS 1977 Altered sensitivity to oxygen toxicity. Am Rev Respir Dis 115:59-65

35. Brooksby GA, Dennis RL, Datnow B, Clark D 1967 Experimental emphysema: Histologic changes and alterations in pulmonary circulation. Calif Med 107:391-395

36. Lee CT, Fein AM, Lippman M, Holtzman H, Kimbel P, Weinbaum G 1981 Elastolytic activity in pulmonary lavage fluid from patients with adult respiratory distress syndrome. N Engl J Med 304:192-196

37. Parsons P, Fowler A, Hyers T, Henson PM 1985 Chemotactic activity in bronchoalveolar lavage fluid from patients with adult respiratory distress syndrome. Am Rev Respir Dis 132:490-493

38. Johanson WG Jr, Seidenfeld JJ, Gomez P, de los Santos R, Coalson JJ 1988 Bacteriologic diagnosis of nosocomial pneumonia following prolonged mechanical ventilation. Am Rev Respir Dis 137:265-272

39. Kapanci Y, Tosco R, Eggerman J, Gould VE 1972 Oxygen pneumonitis in man. Light- and electron-microscopic morphometric studies. Chest 62:162169

40. Bachofen M, Weibel ER 1977 Alterations of the gas exchange apparatus in adult respiratory insufficiency associated with septicemia. Am Rev Respir Dis 116:589-615

41. Kapanci Y, Weibel ER, Kaplan HR, Robinson FR 1969 Pathogenesis and reversibility of the pulmonary lesions of oxygen toxicity in monkeys. II. Ultrastructural and morphometric studies. Lab Invest 20:101-118

42. Crapo JD, Peters-Golden M, Marsh-Salin J, Shelburne JS 1978 Pathologic changes in the lungs of oxygen-adapted rats. A morphometric analysis. Lab Invest 39:640-653

43. Crapo JD, Barry BE, Foscue HA, Shelburne J 1980 Structural and biochemical changes in rat lungs occurring during exposure to lethal and adaptive doses of oxygen. Am Rev Respir Dis 122:123-143

44. Crapo JD 1986 Morphologic changes in pulmonary oxygen toxicity. Annu Rev Physiol 48:721-731 